This is the accepted version of the following article:

Liu J., Morales-Narváez E., Vicent T., Merkoçi A., Zhong G.-H.. Microorganism-decorated nanocellulose for efficient diuron removal. Chemical Engineering Journal, (2018). 354. : 1083 - . 10.1016/j.cej.2018.08.035,

which has been published in final form at https://dx.doi.org/10.1016/j.cej.2018.08.035 @ https://dx.doi.org/10.1016/j.cej.2018.08.035. This manuscript version is made available under the CC-BY-NC-ND 4.0 license http: // creativecommons. org/licenses/by-nc-nd/4.0/ 


\section{Microorganism-decorated Nanocellulose for Efficient Diuron Removal}

Jie Liua, ${ }^{\mathrm{a}}$, Eden Morales-Narváez ${ }^{\mathrm{b}, \mathrm{c}}$, Teresa Vicent ${ }^{\mathrm{d}}$, Arben Merkoçia, b, e ${ }^{*}$, Guo-Hua Zhong ${ }^{\mathrm{b} *}$

${ }^{a}$ Key Laboratory of Crop Integrated Pest Management in South China, Ministry of Agriculture, South China Agricultural University, Guangzhou 510642, P. R. China

${ }^{b}$ Catalan Institute of Nanoscience and Nanotechnology (ICN2), CSIC and BIST, Campus UAB, Bellaterra, 08193 Barcelona, Spain

${ }^{c}$ Biophotonic Nanosensors Laboratory, Centro de Investigaciones en Óptica, A. C., Loma del Bosque 115, Lomas del Campestre, León, Guanajuato, 37150, México.

${ }^{d}$ Departament d'Enginyeria Química, Universitat Autònoma de Barcelona, Bellaterra Barcelona 08193, Spain

${ }^{e}$ Institucio Catalana de Recerca i Estudis Avançats (ICREA), Barcelona 08010, Spain

\footnotetext{
${ }^{*}$ Corresponding authors
}

Email address: arben.merkoci@icn2.cat (A. Merkoçi); guohuazhong@ @scau.edu.cn (G. Zhong) 
ABSTRACT: The environmental impacts of diuron have generated growing interest in remediation methods to prevent the potential threat of diuron to ecosystem integrity and human beings. Here, a simple and effective nanocellulose-based biocomposite coupled with Arthrobacter globiformis D47 as a herbicide degrader is presented for the rapid elimination of diuron. First, bacterium D47 was immobilized on the fiber networks of the nanocellulose, forming a bacteria-decorated nanocellulose (BDN) that outperformed direct utilization of bacterial suspensions for diuron decomposition. More importantly, the advantageous features of BDN could remarkably broaden its applicability since the bio-hybrid material rapidly degraded diuron and its major metabolite 3,4-dichloroaniline at low concentrations $\left(1 \sim 10 \mathrm{mg} \mathrm{L}^{-1}\right)$. In addition, the morphology of BDN revealed the excellent biocompatibility of nanocellulose as cell scaffolding for bacterial proliferation. Then, the adsorption capacity of the nanocellulose and the enzymatic metabolism of the bacteria were validated as a joint mechanism of the BDN biocomposites in the removal of diuron. In addition, the wide applicability of BDN was further verified by the degradation of diuron in environmental matrices and other phenylurea herbicide targets. Therefore, the novel microorganism-immobilized nanocellulose composites provide a promising alternative material combining functional microorganisms with emerging nanomaterials, which may facilitate the bioremediation of organic xenobiotic pollution in complex environments.

KEYWORDS: Biocomposites; Nanocellulose; Bioremediation; Pollutants; Adsorption; Enzymatic degradation 


\section{INTRODUCTION}

With the development of modern agriculture, herbicides are increasingly being employed worldwide, accounting for nearly $50 \%$ of the adopted agrochemicals [1, 2]. Although multiple integrated weed management practices have been encouraged and implemented in crop production, the perceived over-reliance on herbicides has generated concerns among industry, government entities, research scientists and the general public [3, 4]. Moreover, excessive and inappropriate use of herbicides habituated from long-term conventional tillage leads to inevitable residual pollution and frequent herbicide resistance that undermines productivity, sustainability and profitability in agroecosystems [5, 6]. In particular, many studies have warned that herbicides are among the key contributors to pollution stress on non-target organisms with respect to their survival, function and biodiversity since the active ingredients of herbicides and their metabolites have been ubiquitously detected in aquatic, marine and edaphic environments [7-9]._ENREF 9 Nevertheless, microorganisms possess attractive potential to accelerate the breakdown and transformation of organic xenobiotic compounds present in environmental matrices via enzymatic metabolism [10, 11]. In fact, taking advantage of molecular biology, novel bioreactors and immobilization techniques, biodegradation treatments are being remarkably improved due to the enhanced survival of the applied microbes and their ability to degrade, which facilitates the in situ removal of target pollutants $[12,13]$.

Among those methods, immobilization (involving adsorption, entrapment and attachment) is generally considered to be an effective means to improve microbial stability and advantageously maintain their catalytic function $[14,15]$. In this process, a variety of organic/inorganic materials 
have been employed as carriers with their distinct properties that could constitute a relatively stable space for a selected single strain or mixed consortium [16-18]. Due to the lack of flexibility and biocompatibility, however, the ability of immobilized hybrid in contaminant degrading was inhibited for the insufficient cell density and less stability. Recently, bacterial nanocellulose, a biopolymer synthesized by Gluconacetobacter xylinus has thrived in the fields of environmental science, biosensing, biomedicine, engineering and food products as a novel nature-based nanomaterial. Importantly, owing to its extraordinary properties, such as high porosity, inherent renewability, biodegradability, flexibility and great biocompatibility, bacterial nanocellulose offers a desirable culture scaffold for cell proliferation in bioremediation applications [19-21]. For instance, a previous study showed that bacterial nanocellulose could be employed for immobilizing bioluminescent bacteria Alivibrio fischeri, leading to a simple and cost-effective device for rapid screening of hazardous compounds in real matrices [21].

Diuron, a type of phenylurea herbicide (PUH), has been used for weed management in the preand post-germination stages. Because of its stability and sorption to soil, it is persistent and widely detected. As a consequence, diuron has been classified as a major pollutant in the environment [22, 23]. In addition, diuron and its metabolite 3,4-dichloroaniline (3,4-DCA) possess toxicity to organisms with chronic exposure [24-26]. In response, according to a_ENREF_23 previous study, Arthrobacter globiformis D47 was isolated and reported as a diuron-degrading bacterium [27]. However, the application of free bacteria in real environment is limited since the degrading activity could be easily inhibited by multiple factors. Herein, we present an effective, easy-to-fabricate and environmentally friendly biocomposite for diuron removal based on a bacteria-decorated nanocellulose (BDN) consisting of strain $\mathrm{D} 47$ as the biodegrader and nanocellulose as the bio-scaffold. Based on the advantageous nanocellulose, this 
platform could remarkably improve the survival and activity of diuron-degrading bacteria and enhance their applicability in the real environment. First, BDN was fabricated by immobilizing $A$. globiformis D47 in the fiber networks of the nanocellulose. The morphology and diurondegrading ability of the as-prepared BDN were characterized. Next, the mechanism of the diuron elimination by BDN was proposed via the analysis of the absorption and biotransformation processes. Finally, its outstanding potential towards diuron bioremediation was highlighted by the rapid degradation of environmental diuron residue.

\section{MATERIALS AND METHODS}

\subsection{Chemicals}

All the reagents were carefully handled according to their data sheets. Bacterial nanocellulose was purchased from Nanonovin Polymer Co. (Mazandaran, Iran). Standards of PUHs including diuron (98\%), linuron (97\%), chlortoluron (98\%) and isoproturon (98\%) were purchased from Dr. Ehrenstorfer GmbH (Augsburg, Germany). The diuron metabolite 3,4-DCA (98\%) was purchased from Sigma-Aldrich (Taufkirchen, Germany). Each stock solution (1 $\left.\mathrm{g} \mathrm{L}^{-1}\right)$ was prepared in acetonitrile and stored at $4{ }^{\circ} \mathrm{C}$. The mobile solvents for high-performance liquid chromatography (HPLC) and liquid chromatography-mass spectrometry (LC-MS) were purchased from Fisher Scientific, Inc. (Fair Lawn, NJ, USA). An $81 \%$ diuron wettable powder (WP) formulation was obtained from Xinma Biotech (Jinan, China). All other chemicals and reagents used were of analytical grade.

\subsection{Microorganism cultivation}


The lyophilized diuron-degrading bacterium A. globiformis D47 (Code CIP 105365) was ordered from Institut Pasteur-CRBIP (Paris, France). The instructions for strain activation were followed to obtain the single colony in an agar plate, which was then inoculated into Luria-Bertani (LB) medium ( $\mathrm{pH}$ at 7.0). The cell density described as the colony forming units (CFU) was determined by calibrating the respective optical density at $600 \mathrm{~nm}$ that is the $\mathrm{OD}_{600 \mathrm{~nm}}$ of bacterial suspension and colony number of different dilutions in agar plates. The results were fitted by the equation: $y=3.2599 x+6.4904\left(R^{2}=0.984\right)$, where $x$ is the $\mathrm{OD}_{600 \mathrm{~nm}}$ value and $y$ is the cell density $\left(\mathrm{CFU} \mathrm{mL} \mathrm{m}^{-1}\right)$. The procedure for routine cultivation was conducted by inoculating $10 \mu \mathrm{L}$ of a bacterial suspension at 1.4 of $\mathrm{OD}_{600 \mathrm{~nm}}$ (approximately $2.4 \times 10^{11} \mathrm{CFU} \mathrm{mL}^{-1}$ ) into 50 $\mathrm{mL}$ of $\mathrm{LB}$ in a $250-\mathrm{mL}$ Erlenmeyer flask and incubating the suspension on a rotary shaker at 25 ${ }^{\circ} \mathrm{C}$ at $200 \mathrm{rpm}$ for $24 \mathrm{~h}$.

\subsection{Preparation and characterization of $B D N$}

Importantly, the employed nanocellulose was previously characterized in terms of the average fiber diameter $(\sim 45 \mathrm{~nm})$ and length $(\sim 10 \mu \mathrm{m})$. The nanocellulose also exhibited a crystallinity of $82 \%$ and a Young's modulus of $17 \mathrm{GPa}$ [28]. This nanocellulose was cut into 5-mm diameter circular pieces ( $\sim 1 \mathrm{~mm}$ of height) and sterilized at $121{ }^{\circ} \mathrm{C}$ for $20 \mathrm{~min}$. Then, $1 \mu \mathrm{L}$ of the bacterial suspension was inoculated into $100 \mu \mathrm{L}$ of $\mathrm{LB}$ liquid and one nanocellulose piece (that was previously immersed in LB for $2 \mathrm{~h}$ ) in the individual wells of a 96-well microplate. For each substrate, 6 replicates and 6 blanks were used. The $\mathrm{OD}_{600 \mathrm{~nm}}$ values were measured every $4 \mathrm{~h}$ over a 40-h period by a Multiskan ${ }^{\mathrm{TM}}$ FC microplate photometer (Fisher Scientific, USA) to monitor the growth of the D47 strain in the nanocellulose compared to its growth in the liquid medium. The $\mathrm{OD}_{600 \mathrm{~nm}}$ values measured for cell density in BDN was normalized to the bare nanocellulose to exclude the background. In subsequent experiments, nanocellulose pieces were added into 50 
$\mathrm{mL}$ of $\mathrm{LB}$ in a 250 -mL Erlenmeyer flask with $0.1 \%$ inoculum at $25^{\circ} \mathrm{C}$ at $200 \mathrm{rpm}$ for $24 \mathrm{~h}$ to obtain the BDN with homogeneously distributed bacterial cells.

The micromorphology of BDN was observed under scanning electron microscopy (SEM) using a Magellan 400L High Resolution (FEI, Hillsboro, OR, USA). The samples for SEM imaging were prepared by critical point dehydration using ethanol and hexamethyldisilazane (HMDS) for the gradient elution process $[31,32]$.

\subsection{Degradation of durion by $B D N$}

Diuron degradation by adding BDN, free bacteria and bare nanocellulose was evaluated in mineral salt medium (MSM) over 2 days. $1 \mathrm{~mL}$ of the bacterial suspension $\left(\right.$ at $\left.\times 10^{13} \mathrm{CFU} \mathrm{mL}^{-1}\right)$ and the same volume of bare nanocellulose and BDN (about 13 pieces) was added into $50 \mathrm{~mL}$ of diuron-fortified MSM (10 mg L $\left.\mathrm{L}^{-1}\right)$, respectively. All treatments were triplicated and incubated at $25^{\circ} \mathrm{C}$ at $200 \mathrm{rpm}$. The concentrations of diuron and 3,4-DCA in each group was determined every $24 \mathrm{~h}$. In addition, the ability of BDN in degrading a wide range of diuron (at the initial concentrations of 5, 10, 20 and $50 \mathrm{mg} \mathrm{L}^{-1}$ ) was investigated. Diuron-added MSM without BDN was used as a blank treatment. All treatments were triplicated and incubated at $25^{\circ} \mathrm{C}$ at $200 \mathrm{rpm}$. The concentrations of diuron and 3,4-DCA were detected daily over 5 days by HPLC.

\subsection{Chromatographic analysis of durion and 3,4-DCA}

The HPLC analysis was performed using a published method with minor modifications.[29] The samples were analyzed on an Agilent 1260 HPLC (Agilent, USA) equipped with a Kromasil C18 reversed-phase column $(5 \mu \mathrm{m} \times 4.6 \mathrm{~mm} \times 250 \mathrm{~mm})$. The mobile phase was acetonitrile and $0.1 \%$ formic acid $(v: v, 65: 35)$ at $1 \mathrm{~mL} \min ^{-1}$ and $30{ }^{\circ} \mathrm{C}$. The quantitative analysis of the results showed 
that diuron was detected at a wavelength of $252 \mathrm{~nm}$, and its retention time (RT) was $4.51 \mathrm{~min}$. The equation describing the calibration of the diuron concentrations $(x)$ and the chromatographic response values $(y)$ was $\mathrm{y}=92.664 \mathrm{x}+12.341$ (correlation coefficient $\left(R^{2}\right)=0.9983$ ) (see Figure S1 in the Supporting Information, SI). The limit of detection (LOD) was determined as the lowest concentration giving a response three times greater than the signal-to-noise $(\mathrm{S} / \mathrm{N})$ ratio. The limit of quantitation (LOQ) was estimated as 10 times of the $\mathrm{S} / \mathrm{N}$ ratio.[30] The LOD and LOQ of diuron reached $32 \mu \mathrm{g} \mathrm{L}-1$ and $116 \mu \mathrm{g} \mathrm{L}-1$, respectively. For 3,4-DCA, the compound was also detected at a wavelength of $252 \mathrm{~nm}$, and its RT was $5.38 \mathrm{~min}$. The calibration formula was $\mathrm{y}=85.095 \mathrm{x}+10.545\left(R^{2}=0.9991\right)$ (see Figure $\mathrm{S} 2$ in the SI), implying that the HPLC method was reliable and sensitive for the analysis of diuron and its metabolite 3,4-DCA.

\subsection{Adsorption kinetics of diuron}

Diuron adsorption experiments were conducted in batches by adding $0.2 \mathrm{~g}$ of bare nanocellulose at $10.0 \pm 2.0 \%$ of moisture content into $50 \mathrm{~mL}$ of a solution of known diuron concentration (ranging from 0 to $20 \mathrm{mg} \mathrm{L}^{-1}$ respectively) in a 250-mL Erlenmeyer flask with a background electrolyte of $0.1 \mathrm{M} \mathrm{CaCl}_{2}$. Treatments without adding nanocellulose were set as the controls. The capped flasks were placed on a shaker at $150 \mathrm{rpm}$ until the equilibrium was reached, and the temperature was maintained within $25 \pm 1^{\circ} \mathrm{C}$. Next, the adsorption isotherms were investigated by adding 0 to $10.0 \mathrm{~g}$ of bare nanocellulose into $50 \mathrm{~mL}$ of a $20 \mathrm{mg} \mathrm{L}^{-1}$ diuron solution at $25^{\circ} \mathrm{C}$. At a target contact time of $120 \mathrm{~min}$, the suspensions were centrifuged and filtered, and the diuron concentrations in the supernatants were measured by HPLC. Every treatment was carried out in

triplicate. To analyze the adsorption process, the equilibrium adsorption capacity $\left(q_{e}, \mathrm{mg} \mathrm{g}^{-1}\right)$ was calculated as the following equation (Eq. 1) 


$$
q_{e}=V\left(C_{0}-C_{e}\right) / m
$$

where $C_{0}$ and $C_{e}\left(\mathrm{mg} \mathrm{L}^{-1}\right)$ are the initial and equilibrium diuron concentrations in the aqueous solution, $V(\mathrm{~mL})$ is the volume of the solution, and $m(\mathrm{mg})$ is the cellulose mass. Efficiency of adsorption $\left(E_{a d}, \%\right)$ was calculated according to the following equation (Eq. 2)

$$
E_{a d}=100\left(C_{0} V_{0}-C_{e} V_{e}\right) / m
$$

The adsorption kinetics were investigated using the pseudo-first-order and pseudo-second-order models at 25 and $40{ }^{\circ} \mathrm{C}$, respectively. Furthermore, the applicability of the Langmuir and Freundlich isotherms was validated by the modeling methods. The analysis of related parameter was provided in Table S1 (see SI).

\subsection{Detection and identification of diuron biodegradation products by $B D N$}

The metabolic products were collected and identified to model the transformation pathway during the enzymatic degradation of diuron. BDN was inoculated into $50 \mathrm{~mL}$ of a diuron-spiked medium at $10 \mathrm{mg} \mathrm{L}^{-1}$ and placed on a rotary shaker at $200 \mathrm{rpm}$ at $25^{\circ} \mathrm{C}$. Every $1 \mathrm{~mL}$ of liquid sample was collected at intervals of 12, 24 and $48 \mathrm{~h}$ after incubation and centrifuged at 10000 $\mathrm{rpm}$ for $20 \mathrm{~min}$. The supernatant was filtered using syringes with nitro-cellulose membrane $(0.22$ $\mu \mathrm{m}, \mathrm{CNW}$, Shanghai, China) into a $1.5 \mathrm{~mL}$ vial to remove bacteria cells or other fragments before analyzing by liquid chromatography tandem mass spectrometry (LC-MS/MS) (Agilent 1290-6545 UHPLC-Q-TOF, Agilent, USA). The byproducts were analyzed with an Agilent ZORBAX Eclipse Plus C18 column $(100 \times 2.1 \mathrm{~mm}, 1.8 \mu \mathrm{m})$ by following a previously reported method.[33, 34] Methanol and $0.1 \%$ formic acid $(v: v, 65: 35)$ were used as the mobile phase. The $\mathrm{m} / \mathrm{z}$ of diuron is $233.02 \mathrm{Da}$, and the detection of the fragments by mass spectrometry was 
scanned under both the positive and negative ion modes with an $\mathrm{m} / \mathrm{z}$ range of 50 500 Da. The chemical structures of the daughter ions with high richness were analyzed to propose the biodegradation pathway of diuron.

\subsection{Diuron degradation in environmental matrices}

The availability of BDN during the diuron degradation was evaluated in three environmental samples, namely, the water and soil in an agroecosystem and the surrounding surface water. Briefly, for each matrix, two experimental stages were studied under sterilized and non-sterilized conditions, sequentially. In the first stage, the test substrate was previously purified and sterilized by autoclaving at $121{ }^{\circ} \mathrm{C}$ for $20 \mathrm{~min}$ to exclude uncertain factors from the matrix. Then, in the second stage, the degradation test was conducted in untreated environmental samples to reveal the practical performance of $\mathrm{BDN}$ composites. It is generally accepted that the bioremediation of contaminants by active bacteria is more effective and rapid in sterile conditions than in nonsterile conditions since the enzymatic degradation is easily affected by multiple environmental factors. Therefore, the experimental period in sterile samples was set within $48 \mathrm{~h}$ to more precisely evaluate the changes in the concentrations of diuron and 3,4-DCA. However, the degradation process was slower in non-sterilized environmental samples for the impacts of external factors, so the experimental period was set within 5 days when studying the removal of diuron in unsterile environmental samples.

First, the water samples were collected from a paddy field in Duhu Village, Guangdong, China. After being filtered and sterilized, $1 \mathrm{~mL}$ of the bacterial suspension (at $\times 10^{13} \mathrm{CFU} \mathrm{mL}^{-1}$ ) and the same volume of BDN (at 13 pieces and the cell density at $\times 10^{13} \mathrm{CFU} \mathrm{mL}$ ) was added into 50 $\mathrm{mL}$ of diuron at an initial concentration of $5 \mathrm{mg} \mathrm{L}^{-1}$. The non-bacteria-supplemented group was 
set as the control, and each treatment was performed in triplicate. The concentrations of the residual diuron were measured at the intervals of 2, 24 and $48 \mathrm{~h}$ by HPLC. In the second stage, the same dosage of BDN were added into $50 \mathrm{~mL}$ of the untreated water with diuron at initial concentrations of 1,5 and $10 \mathrm{mg} \mathrm{L}^{-1}$. The triplicate samples and treatments without BDN were used as the controls. After incubation on a shaker, residual diuron was monitored within $5 \mathrm{~d}$ by HPLC. Next, the soil samples were collected in Duhu Village, Guangdong, China. In addition, the surface water was sampled from a river close to farm land in Boluo, Guangdong, China. The experimental protocol was followed as mentioned before.

\subsection{Degradation of other PUHs by BDN}

Diuron belongs to a group of agrochemicals called PUHs, which include various commercial types. Here, the degradation ability of BDN was further investigated to other PUHs, including linuron, chlortoluron and isoproturon. 13 pieces of BDN were added into $50 \mathrm{~mL}$ of MSM medium with each herbicide at an initial concentration of $5 \mathrm{mg} \mathrm{L}^{-1}$. Additionally, $1 \mathrm{~mL}$ of the bacterial suspension (at $\times 10^{13} \mathrm{CFU} \mathrm{mL}^{-1}$ ) and the same volume of bare nanocellulose (at 13 pieces) was added into $50 \mathrm{~mL}$ of herbicide-fortified samples (at an initial concentration of $5 \mathrm{mg}$ $\mathrm{L}^{-1}$ ). The same medium without supplement was used as a blank treatment, and all treatments were conducted in triplicate. After incubation, the residual concentrations were determined after 24 and $48 \mathrm{~h}$. The quantification methods for the three herbicides were validated by HPLC (shown in SI Figure S3).

\section{RESULTS AND DISCUSSION}

\subsection{Characterization of BDN}


Bioremediation by microorganisms harnessing xenobiotic compounds as their sole carbon and/or nitrogen source is one of the most advantageous methods for the permanent clean-up of environmental contaminants $[11,35]$. When applying those microorganisms directly to the environment, the biodegradation performance could be easily inhibited by a variety of factors, such as the instability and decreased functionality of the introduced microbes under changeable environmental circumstances. To tackle the survival and activity of pollutant-degrading bacteria, nanomaterials with excellent properties may offer exciting possibilities. In Figure 1a, $A$. globiformis D47 bacteria demonstrated typical sigmoidal growth after being inoculated into portions of nanocellulose, where they experienced lag, exponential and stationary phase sequentially over $40 \mathrm{~h}$. In the BDN, the D47 strain reached the highest cell density (approximately $4.6 \times 10^{13} \mathrm{CFU} \mathrm{mL} \mathrm{m}^{-1}$ ) within 36 to $40 \mathrm{~h}$, showing the same growth tendency as that of the cultivation in the liquid medium.

Next, we evaluated the degradation of diuron using BDN in MSM while the control effects of free bacteria and bare nanocellulose were simultaneously monitored. As shown in Figure 1b, the decline of diuron by free bacteria was significant that $86.5 \%$ of initial diuron (at $10 \mathrm{mg} \mathrm{L}^{-1}$ ) was degraded in $48 \mathrm{~h}$ with the accumulation of the metabolite 3,4-DCA, indicating that the enzymatic degradation mainly contributed to the reduction of diuron by free bacteria. In the treatment of bare nanocellulose, the residual diuron stabilized at approximately $7.0 \mathrm{mg} \mathrm{L}^{-1}$ after $48 \mathrm{~h}$ without 3,4-DCA detected, suggesting the removal of diuron by free nanocellulose was most likely caused by reaching the equilibrium of physical adsorption. On the other hand, diuron decreased more rapidly in the treatment of BDN with a high removal percentage (above 90\%) in $48 \mathrm{~h}$, implying the combination of bacteria and nanocellulose may provide the BDN hybrids with a synergistic effect in diuron removal. In addition, the ability of BDN in degrading a range of 
diuron (initially at 1 to $50 \mathrm{mg} \mathrm{L}^{-1}$ ) was studied since the residual levels of diuron may differ widely when applying BDN in the real environment. From Figure 1c, the concentration of diuron was dramatically decreased; in fact, approximately $99 \%$ of the fortified diuron was removed within $3 \mathrm{~d}$.

Along with the diuron degradation, the distinct accumulation of its metabolite 3,4-DCA was monitored over $5 \mathrm{~d}$ and gradually declined after the 2-day period (Figure 1d). Since the peak levels of 3,4-DCA were positively correlated with the initial diuron in each treatment, 3,4-DCA could be the most common byproduct formed during diuron biodegradation, which is consistent with previous investigations.[26, 36]_ENREF_32 After further optimized by single-factor experiments, the final prepared BDN demonstrated an improved degradation efficiency with $85 \%$ of the added diuron (initially at 1 to $50 \mathrm{mg} \mathrm{L}^{-1}$ in MSM) being removed after $24 \mathrm{~h}$ of treatment (in SI Figure S4 and Table S2). Therefore, these results indicate that BDN composites were able to rapidly degrade diuron, especially at low residual levels, which may endow these composites with a more advantageous performance against diuron pollution at environmentally relevant levels.

Because of the proliferation of the immobilized D47 strain, BDN showed higher turbidity than the transparent untreated nanocellulose, as determined by visual observations. In Figure $2 \mathrm{a}$, the SEM images illustrate that bare nanocellulose consisted of abundant and uniform nanofibers that formed a stable and flexible net structure. After immobilization, the network of nanocellulose remained rich and cross-linked but was densely filled with bacteria (Figure 2b). Interestingly, two typical shapes of A. globiformis (irregular rods and spheres) were captured by SEM, clarifying the excellent flexibility and impressive biocompatibility of the nanocellulose (Figure 2b, 2c). Thus, nanocellulose was qualified as an ideal bio-support for A. globiformis D47 
immobilization to fabricate the BDN composites as simple and efficient bioreactors in diuron removal.

\subsection{Diuron adsorption kinetics and isotherms with nanocellulose}

Nanocellulose is a linear polysaccharide that consists of methylol and hydroxyl groups in each repeating molecular unit. These functional groups endow the biopolymer with excellent hydrophilicity and an affinity towards xenobiotic compounds [37]. To determine the mechanism of diuron removal by the $\mathrm{BDN}$ biocomposites, a series of experiments were conducted to analyze the adsorption of diuron by bare nanocellulose material. First, the plots of $Q_{t}$ versus time for various initial concentrations of diuron $\left(5,10\right.$ and $\left.20 \mathrm{mg} \mathrm{L}^{-1}\right)$ are presented in Figure 3a. The absorption capacity of the nanocellulose increased dramatically with time and reached equilibrium in $3 \mathrm{~h}$. After $5 \mathrm{~h}$ of contact time, the $Q_{t}$ values reached a plateau at 4.7, 2.7 and 1.6 $\mathrm{mg} \mathrm{g}^{-1}$ and remained stable afterwards. From the calculation of the $E_{a d}$, the values ranged from $25.2 \%$ to $33.4 \%$, and a higher efficiency of absorption was found at a lower initial diuron concentration, which indicated that the nanocellulose was capable of effectively adsorbing a range of diuron residue concentrations, particularly at environmentally relevant concentrations. Then, the adsorption kinetics were investigated to describe the diuron absorption rate under different temperatures (at 25 and $40{ }^{\circ} \mathrm{C}$ ), which was fitted linearly by using the pseudo-first-order and pseudo-second-order models (Figure 3b, 3c). The kinetics parameters obtained are summarized in Table 1. From the two models, the $R^{2}$ values were calculated in the range of 0.887 to 0.997 , and higher coefficients were determined via the pseudo-second-order kinetics model with more accordant $Q_{e}$ values at the theoretical and experimental levels. Therefore, the results indicate that the diuron uptake in nanocellulose can be described well using the pseudo-secondorder model, suggesting that the adsorption process was more likely controlled by the 
chemisorption behavior, which was in good agreement with previous studies of pollutant adsorption using cellulose-based nanocomposites [38-40].

In addition, the adsorption isotherms of diuron on nanocellulose was also examined at $25^{\circ} \mathrm{C}$ according to the Langmuir and Freundlich isotherms (Figure 3d, 3e). The equilibrium data was then linearly fitted by the two classic models, which provided a greater understanding of the interaction between the adsorbate and adsorbent. The Langmuir isotherm is valid for monolayer adsorption on a homogeneous surface with equivalent and identical sites, whereas the Freundlich model interprets multilayer adsorption on a heterogeneous surface with interactions between the adsorbate molecules and the adsorbent.[40] According to the model parameters, as shown in Table 1, the equilibrium data were well fitted in two models with $R^{2}$ values of 0.966 and 0.987 , respectively. Interestingly, the simulated $Q_{m}$ (at $0.536 \mathrm{mg} \mathrm{g}^{-1}$ ) from the Langmuir plot was different from the experimental data (at $1.573 \mathrm{mg} \mathrm{g}^{-1}$ ), suggesting that the adsorption of diuron onto nanocellulose was not solely promoted by the monolayer-forming adsorption. In addition, the constant $1 / n$ from the Freundlich model was above 1.0 (at 1.091), reflecting that the adsorption of diuron was more likely a multilayer chemical process with a non-uniform distribution of absorption sites over the heterogeneous nanocellulose surface. This feature, also in accordance with previous kinetics analyses, could be attributed to the affinity of the functional groups on the cellulose chains. In summary, the efficient adsorption capacity of nanocellulose, serving as an important part of the diuron removal mechanism, facilitated the rapid elimination of diuron in contaminated environments by the BDN biocomposites.

\subsection{Identification of metabolites during diuron biodegradation}


According to the aforementioned results, the adsorption capacity of BDN's carrier nanocellulose was validated, but it only partially contributed to the removal of diuron. The key mechanism of diuron elimination by BDN was still unclear. Given that BDN was assembled by carrier material and bacteria D47, the influence of the latter component was investigated through the identification of byproducts formed during the biodegradation of diuron since the microbial transformation is reported as the most efficient way to decompose diuron in a natural environment [22]. As shown in SI Figure S5, five compounds with high abundance were detected from the LC-MS/MS analysis. Compound I eluted at RT 4.82 min with a characteristic mass fragment at $\mathrm{m} / \mathrm{z} 233$, which exactly matched the parent ion of diuron. Therefore, compound I was identified as diuron. The remaining four compounds were characterized as $N, N$-dimethyl$N$-phenylurea, 3-(3-chloro-4-hydroxyphenyl)-1,1-dimethylurea, $\quad$ 1-(3,4-dichlorophenyl)-3formylurea and 3,4-DCA, respectively, based on the similarity of their retention times and molecular ions (in SI Table S3).

Based on the chemical structure of diuron and those of the identified intermediates, the degradation pathway of diuron by BDN was identified as shown in Figure 4. Initially, the aromatic ring of diuron is dechlorinated and oxidized, sequentially forming 3-(3-chloro-4hydroxyphenyl)-1,1-dimethylurea and $N, N$-dimethyl- $N$-phenylurea. Furthermore, diuron is decomposed by methyl oxidation and demethylation, followed by the cleavage of the C-N bond to produce its major metabolite 3,4-DCA, which agrees well with previous studies on the biotic degradation of diuron [11, 41]. Additionally, various fragments having small molecular masses were detected in the LC-MS/MS analysis, which implied that the aforementioned metabolites could eventually break down into compounds with simple structures that may impose less toxicity to the environment. Since the BDN biocomposites were decorated with the D47 strain, 
the functional bacteria could efficiently drive the rapid degradation process, and thus enzymatic degradation functioned as the major mechanism of diuron removal by prepared BDN.

\subsection{Diuron degradation in real environmental matrices}

Due to the potential threat to non-target organisms caused by residual diuron, it is essential and necessary to investigate whether BDN possesses the capacity to remove and degrade diuron accumulated in different environments. Therefore, the elimination of diuron was evaluated in three matrices that were easily exposed to diuron residue. According to our two-stage design, the degradation capacity of BDN was validated, where water and soil from a farming region and the surrounding surface water were applied as the test matrices, which were spiked with a range of diuron concentrations (initially from 1 to $10 \mathrm{mg} \mathrm{kg}^{-1} / \mathrm{mg} \mathrm{L}^{-1}$ ) (Figure 5). To be specific, BDN was first added into sterilized paddy field water spiked with diuron at an initial concentration of $5 \mathrm{mg} \mathrm{L}^{-1}$, and the bacterial suspension was introduced for comparison. Although the residual concentration of diuron decreased rapidly in both treatments with time, the removal rate of the BDN-treated group was higher than that of the pure bacterial treatment possibly because of the adsorption of the nanocellulose scaffold (in Figure 5a). After $48 \mathrm{~h}$, diuron was not detected in either treatment, whereas the compound remained in the control sample. Meanwhile, the major intermediate 3,4-DCA appeared over $24 \mathrm{~h}$ and then gradually declined, which further supports the concept that the elimination of environmental diuron by BDN could be a result of the joint action of microbial degradation and material adsorption. Figure 5b illustrates the degradation process of diuron by the BDN biocomposites applied in original paddy field water in the second stage, showing the rapid reduction of this herbicide within $5 \mathrm{~d}$. In the same period, the accumulation of the 3,4-DCA metabolite increased rapidly, peaked after $2 \mathrm{~d}$ and subsequently decreased, which agrees well with the investigation in the first stage. 
In addition, the soil collected from the paddy field was also applied as another environmental matrix for diuron degradation. Following a similar protocol, diuron and its metabolite 3,4-DCA were effectively removed by the BDN biocomposites (Figure $5 \mathrm{c}, 5 \mathrm{~d}$ ), but the degradation efficiency was less significant compared to the treatment in aqueous conditions since a very small amount of diuron residue $\left(<0.5 \mathrm{mg} \mathrm{kg}^{-1}\right)$ was still detected after $5 \mathrm{~d}$, which could be a result of the slower mobility of the degrader in the soil environment. Nevertheless, the degradation process was much faster than its natural dissipation $[11,22]$, suggesting that the application of BDN could remarkably facilitate the elimination of diuron in soil. Meanwhile, the performance of diuron removal was further validated in river water as the reaction matrix. Likewise, diuron residue and its more toxic metabolite 3,4-DCA were rapidly decomposed with the addition of BDN biocomposites (Figure e, 5f). Overall, the application of BDN demonstrated outstanding removal of diuron pollution in various environments, which highlighted the advantageous and competitive potential of BDN in eliminating the possible threats resulting from diuron residue.

\subsection{Degradation of other PUHs}

For decades, PUHs have been developed into a variety of commercial materials to become one of the most commonly used chemical families for both the pre- and post-emergence control of weeds in agricultural crops, as well as for public maintenance $[42,43]$. To explore the utilization of BDN in remediation of this family, three common PUHs were applied as the target compounds, namely, chlortoluron, linuron and isoproturon. As shown in Table 2, BDN exhibited rapid degradation of chlortoluron and isoproturon. Greater than $90 \%$ of herbicides were degraded within $48 \mathrm{~h}$, whereas the degradation rate of linuron only reached $50.2 \%$. Despite the lower efficiency compared to the removal of the former PUHs, the removal of linuron residue by BDN 
was sufficiently effective, demonstrating its potential for practical applications. Hence, the prepared BDN biocomposites displayed low substrate specificity, meaning that multiple PUHs could be applied as its targets. Besides, the fact that PUHs were more efficiently degraded by BND than free bacteria and bare nanocellulose may suggest that the hybrids facilitated a synergistic degradation on PUHs, which could largely broaden the availability and applicability of the BDN composites for the removal of environmental PUH contamination.

\section{CONCLUSION}

In summary, the present BDN hybrids demonstrated more efficient degradation and wider applicability in the remediation of diuron pollution than the direct use of free bacteria and bare nanocellulose. The adsorption capacity of the nanocellulose and the enzymatic metabolism of the bacteria jointly contributed to the rapid removal by BDN in the environmental samples. The results also exhibited the potential and advantages of the BDN method employing functional microorganisms combined with emerging nanomaterials, which may facilitate the bioremediation of organic xenobiotic pollution in complex environmental matrices. 


\section{FIGURES}

a)

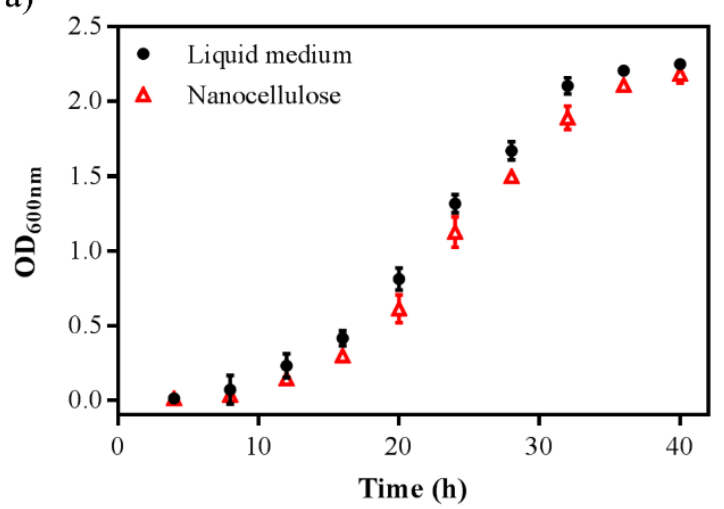

c)

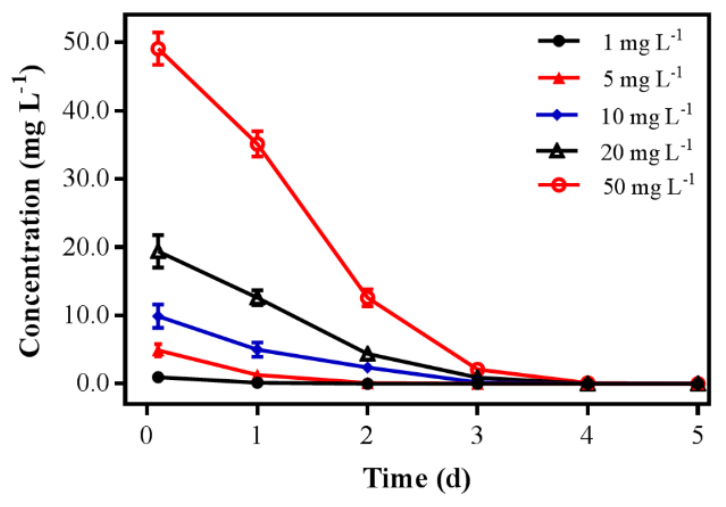

b)

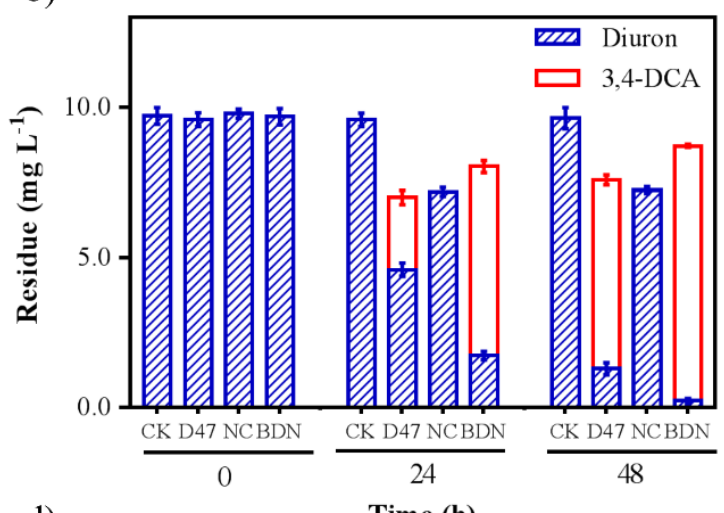

d)

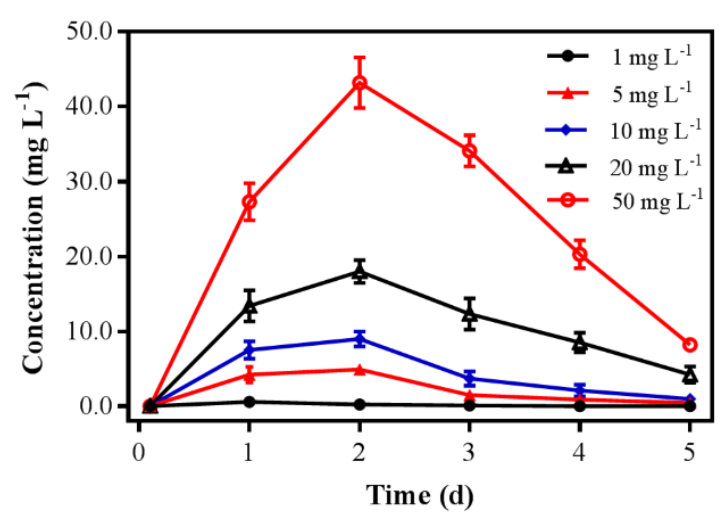

Figure 1. Characterization of BDN. (a) The growth tendency of A. globiformis D47 in liquid medium and nanocellulose. (b) Degradation of diuron (at initial $10 \mathrm{mg} \mathrm{L}^{-1}$ ) by free bacteria D47, bare nanocellulose (NC) and BDN. (c) Degradation of diuron at initial 1 50 mg L-1 by BDN. (d) The accumulation of 3,4-DCA during the degradation of diuron. 
a)

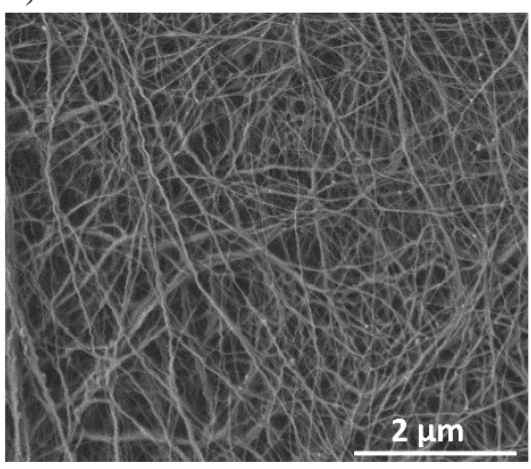

b)

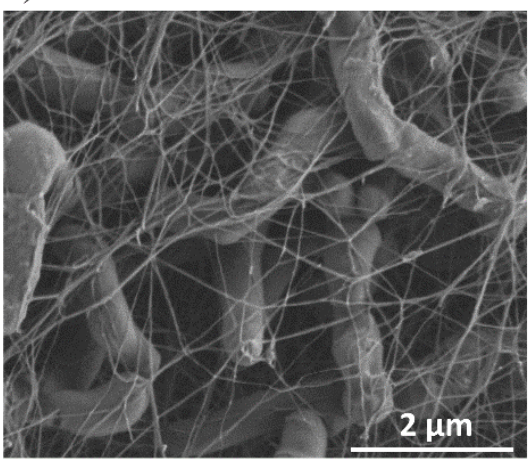

c)

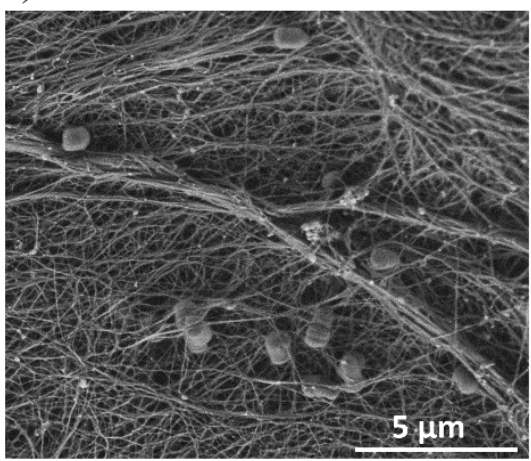

Figure 2. Micromorphology of BDN. (a) SEM image of bare nanocellulose. (b-c) SEM images of BDN. 
a)

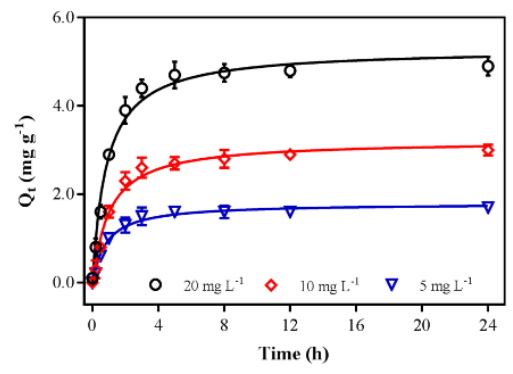

d)

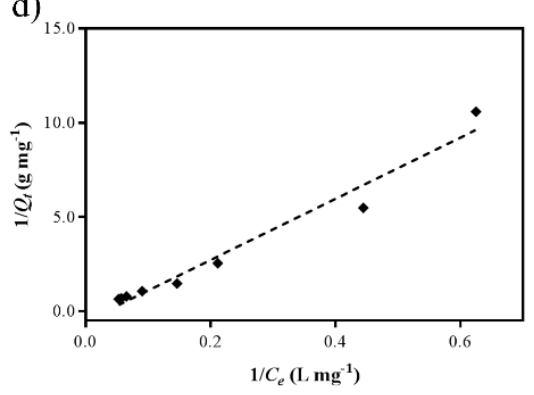

b)

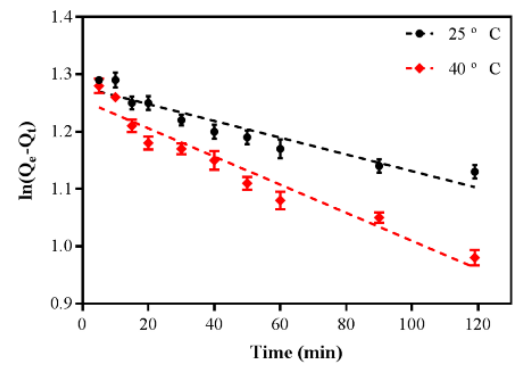

c)

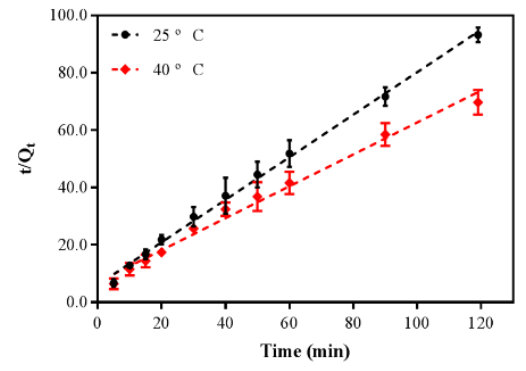

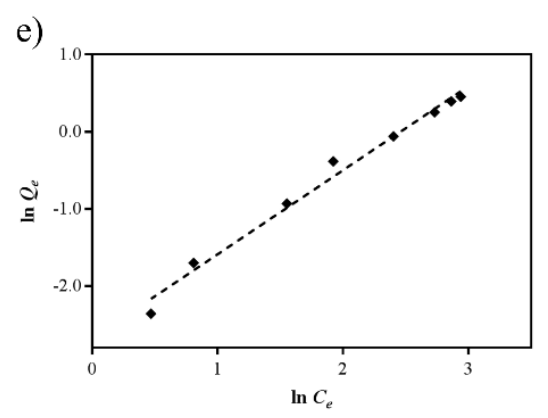

e)

Figure 3. Diuron adsorption by bare nanocellulose. (a) Adsorption equilibrium of diuron at various initial concentrations. (b) Pseudo-first-order model. (c) Pseudo-second-order model. (d) Langmuir isotherm. (e) Freundich isotherm. 


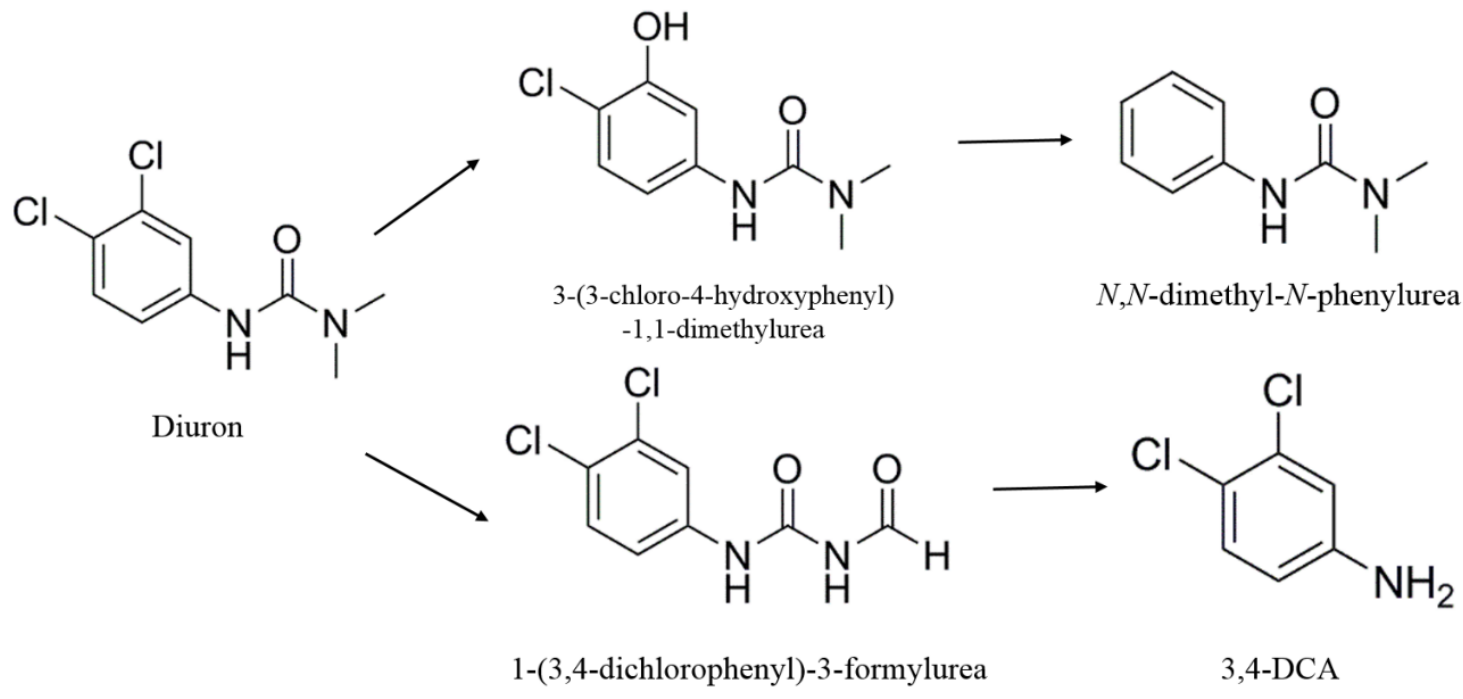

Figure 4. The proposed degradation pathway for diuron by the BDN biocomposites. 
a)
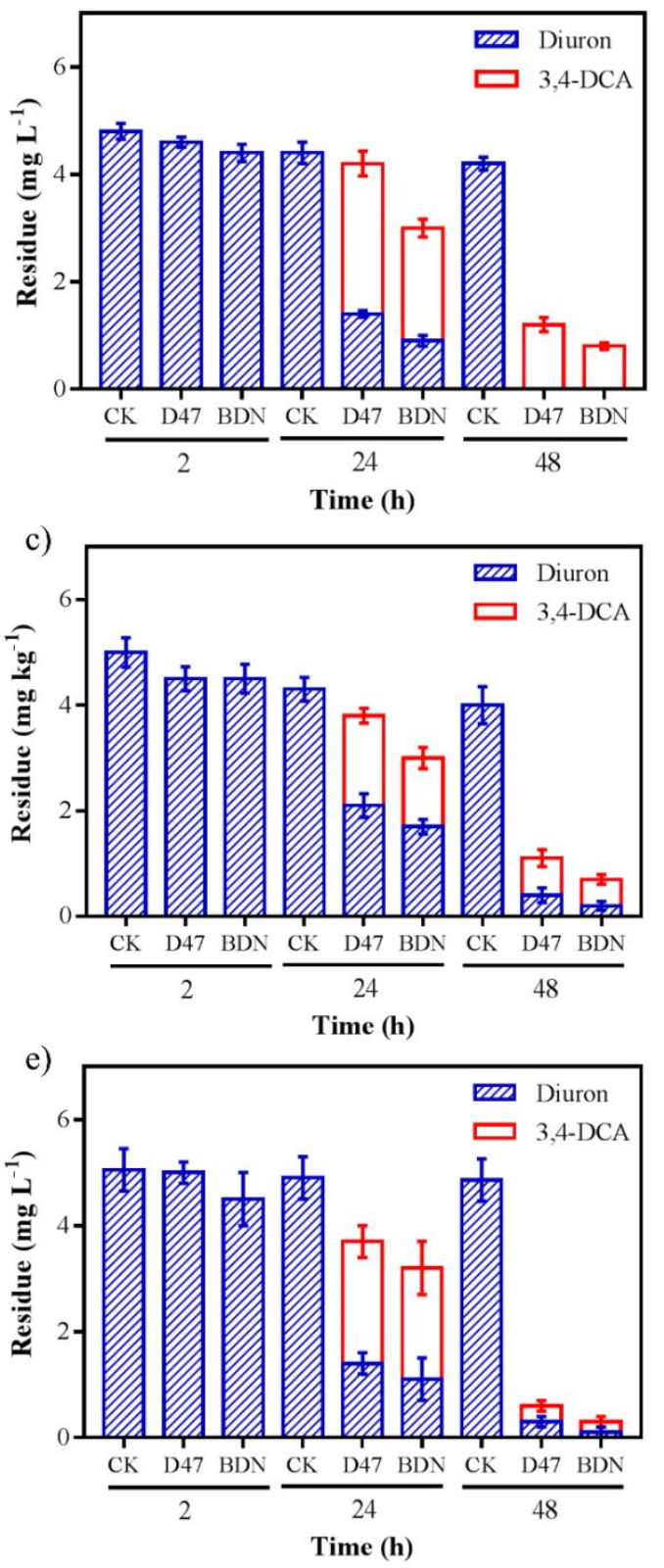

b)

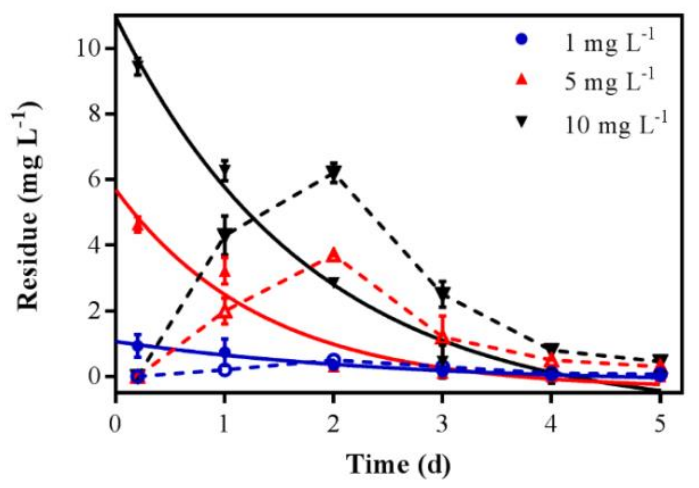

d)

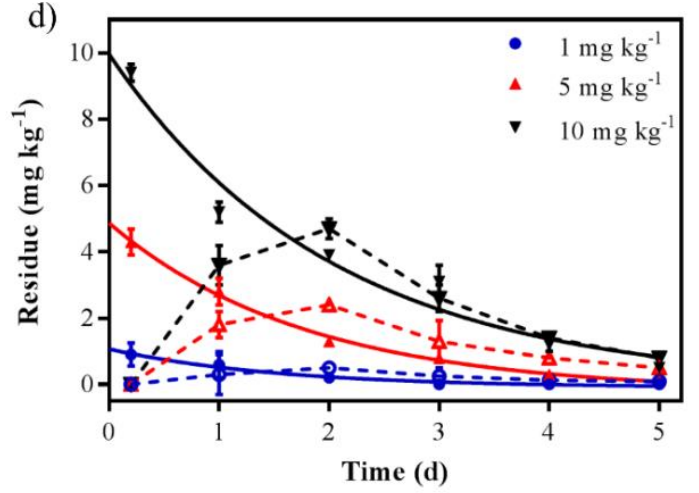

f)

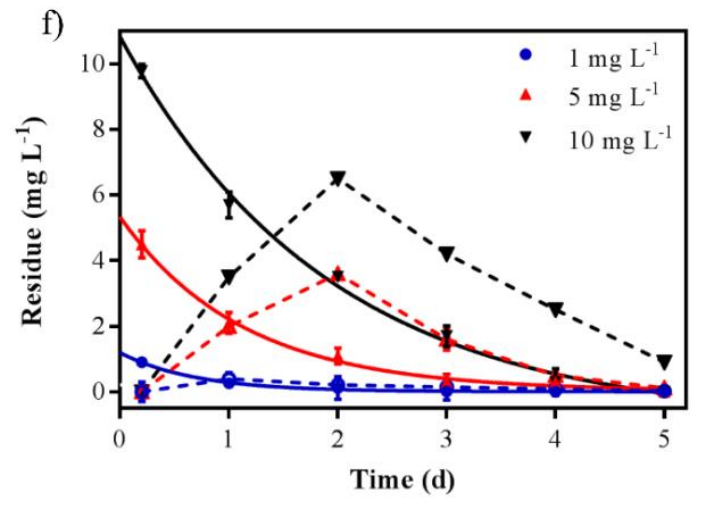

Figure 5. Diuron removal by BDN in environmental matrices. (a) In sterilized and (b) original paddy field water; (c) in sterilized and (d) original paddy field soil; and (e) in sterilized and (f) original river water. In $\mathrm{b}, \mathrm{d}$ and $\mathrm{f}$, the solid lines represent the residue of diuron, while the dashed lines are the concentration of 3,4-DCA in related treatments. 


\section{TABLES}

Table 1. Parameters of the kinetics and isotherms for diuron adsorption onto bare nanocellulose

\begin{tabular}{|c|c|c|c|c|c|c|}
\hline & lysis & $\begin{array}{c}\text { Temperature } \\
\left({ }^{\circ} \mathrm{C}\right)\end{array}$ & $\begin{array}{c}Q_{e, \exp } \\
\left(\mathrm{mg} \mathrm{g}^{-1}\right)\end{array}$ & $\begin{array}{c}Q_{e, \mathrm{cal}} \\
\left(\mathrm{mg} \mathrm{g}^{-1}\right)\end{array}$ & $k$ & $R^{2}$ \\
\hline \multirow{4}{*}{ Kinetics } & \multirow{2}{*}{ Pseudo-first-order } & 25 & 1.46 & 1.28 & $0.0014 \mathrm{~min}^{-1}$ & 0.887 \\
\hline & & 40 & 1.69 & 1.56 & $0.0025 \mathrm{~min}^{-1}$ & 0.932 \\
\hline & \multirow{2}{*}{ Pseudo-second-order } & 25 & 1.46 & 1.35 & $0.0908 \mathrm{~g} /\left(\mathrm{mg} \mathrm{min}^{-1}\right)$ & 0.997 \\
\hline & & 40 & 1.69 & 1.80 & $0.0445 \mathrm{~g} /\left(\mathrm{mg} \mathrm{min}^{-1}\right)$ & 0.988 \\
\hline \multirow{2}{*}{ Isotherm } & Langmuir & 25 & 1.57 & - & $16.26 \mathrm{~L} \mathrm{~g}^{-1}$ & 0.966 \\
\hline & Freundich & 25 & 1.57 & - & $14.61 \mathrm{mg} \mathrm{g}^{-1}$ & 0.987 \\
\hline
\end{tabular}

Note: $Q_{e, \text { exp }}$ is the actual adsorption determined in the experiments, and $Q_{e, \text { cal }}$ is the calculated value according to the kinetic models.

The $k$ values represent the constants of the pseudo-first-order kinetics, pseudo-second-order kinetics, and Langmuir and Freundich isotherms. 
Table 2. The degradation of various PUHs by BDN, free bacteria and bare nanocellulose

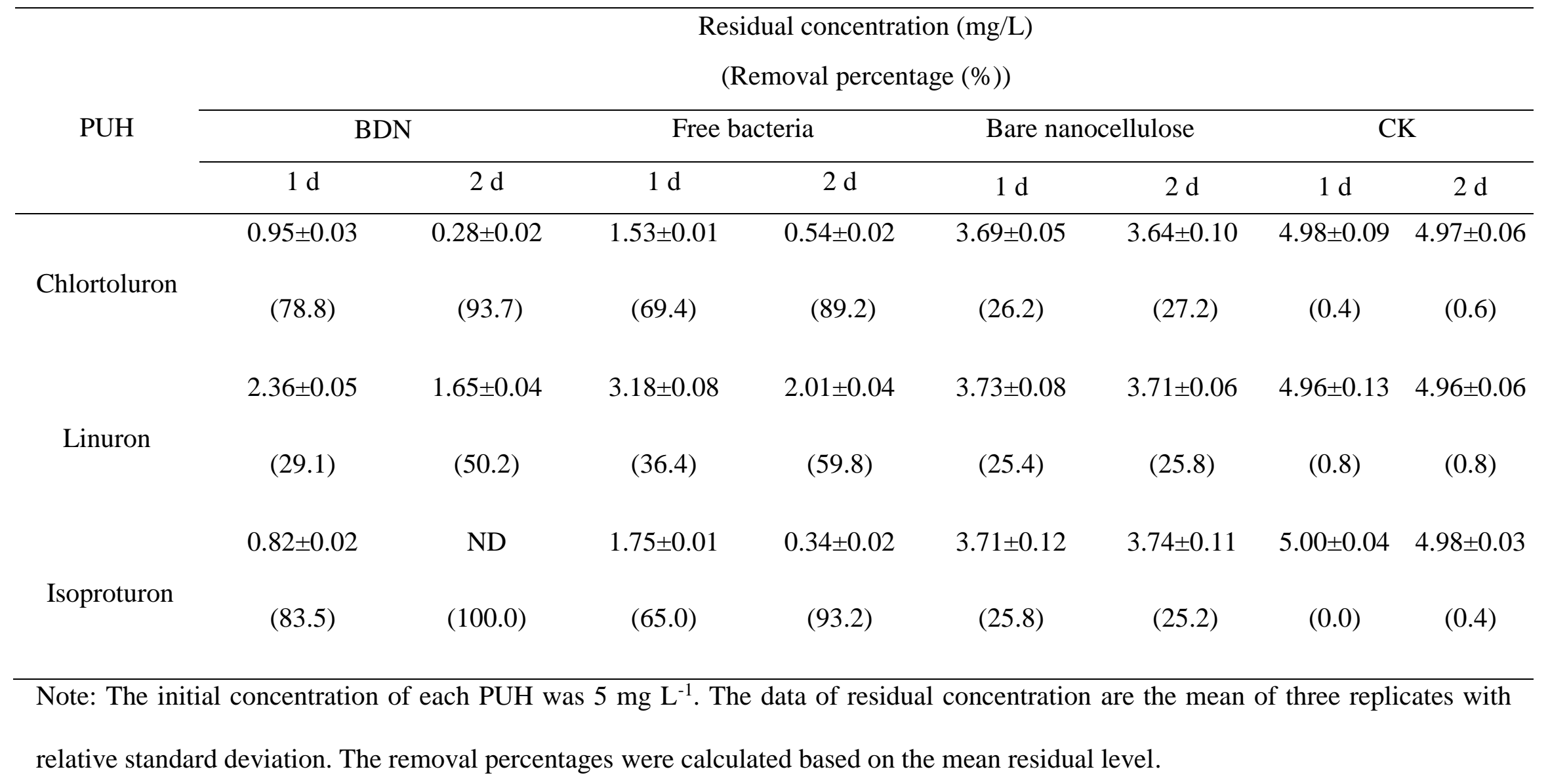




\section{ACKNOWLEDGMENTS}

This work was supported by the National Natural Science Foundation of China (No. 31371960)

and the Guangdong Province Science and Technology Plan Project (No. 2015B020207003).

ICN2 is funded by the CERCA Programme / Generalitat de Catalunya, and we acknowledge the support from the Severo Ochoa Program (MINECO, Grant SEV-2013-0295) and the Spanish MINECO under project MAT2017-87202-P. EMN acknowledges the financial support from CONACYT (Mexico, Grant 293523).

\section{REFERENCES}

[1] L.P. Gianessi, The increasing importance of herbicides in worldwide crop production, Pest Management Science 69 (2013) 1099-1105.

[2] F. Le Bellec, A. Vélu, P. Fournier, S. Le Squin, T. Michels, A. Tendero, C. Bockstaller, Helping farmers to reduce herbicide environmental impacts, Ecological Indicators 54 (2015) 207-216.

[3] A.R. Kniss, Long-term trends in the intensity and relative toxicity of herbicide use, Nature Communications 8 (2017) 14865.

[4] J.R. Lamichhane, Y. Devos, H.J. Beckie, M.D.K. Owen, P. Tillie, A. Messéan, P. Kudsk, Integrated weed management systems with herbicide-tolerant crops in the European Union: lessons learnt from home and abroad, Critical Reviews in Biotechnology 37 (2017) 459-475.

[5] J.A. Evans, P.J. Tranel, A.G. Hager, B. Schutte, C. Wu, L.A. Chatham, A.S. Davis, Managing the evolution of herbicide resistance, Pest Management Science 72 (2016) 74-80.

[6] H. Darmency, N. Colbach, V. Le Corre, Relationship between weed dormancy and herbicide rotations: implications in resistance evolution, Pest Management Science 73 (2017) 1994-1999.

[7] N.J. Diepens, E. Buffan-Dubau, H. Budzinski, J. Kallerhoff, G. Merlina, J. Silvestre, I. Auby, T. Nathalie, A. Elger, Toxicity effects of an environmental realistic herbicide mixture on the seagrass Zostera noltei, Environmental Pollution 222 (2017) 393-403.

[8] M. Hijosa-Valsero, E. Bécares, C. Fernández-Aláez, M. Fernández-Aláez, R. Mayo, J.J. Jiménez, Chemical pollution in inland shallow lakes in the Mediterranean region (NW Spain): PAHs, insecticides and herbicides in water and sediments, Science of The Total Environment 544 (2016) 797-810. 
[9] L. Marie, P. Sylvain, G. Benoit, M. Maurice, I. Gwenaël, Degradation and Transport of the Chiral Herbicide S-Metolachlor at the Catchment Scale: Combining Observation Scales and Analytical Approaches, Environmental Science \& Technology 51 (2017) 13231-13240.

[10] L. Carles, F. Rossi, M. Joly, P. Besse-Hoggan, I. Batisson, J. Artigas, Biotransformation of herbicides by aquatic microbial communities associated to submerged leaves, Environmental Science and Pollution Research 24 (2017) 3664-3674.

[11] S. Hussain, M. Arshad, D. Springael, S.R. SøRensen, G.D. Bending, M. Devers-Lamrani, Z. Maqbool, F. Martin-Laurent, Abiotic and Biotic Processes Governing the Fate of Phenylurea Herbicides in Soils: A Review, Critical Reviews in Environmental Science and Technology 45 (2015) 1947-1998.

[12] M. Herrero, D.C. Stuckey, Bioaugmentation and its application in wastewater treatment: A review, Chemosphere 140 (2015) 119-128.

[13] J. Liu, W. Huang, H. Han, C. She, G. Zhong, Characterization of cell-free extracts from fenpropathrin-degrading strain Bacillus cereus $\mathrm{ZH}-3$ and its potential for bioremediation of pyrethroid-contaminated soils, Science of The Total Environment 523 (2015) 50-58.

[14] Y. Chen, B. Yu, J. Lin, R. Naidu, Z. Chen, Simultaneous adsorption and biodegradation $(\mathrm{SAB})$ of diesel oil using immobilized Acinetobacter venetianus on porous material, Chemical Engineering Journal 289 (2016) 463-470.

[15] Z. Bayat, M. Hassanshahian, S. Cappello, Immobilization of microbes for bioremediation of crude oil polluted environments: A mini review, The Open Microbiology Journal 9 (2015) 48-54. [16] J. Liu, S. Chen, J. Ding, Y. Xiao, H. Han, G. Zhong, Sugarcane bagasse as support for immobilization of Bacillus pumilus HZ-2 and its use in bioremediation of mesotrionecontaminated soils, Applied Microbiology and Biotechnology 99 (2015) 10839-10851.

[17] Z. Ma, C. Li, H. Su, Dark bio-hydrogen fermentation by an immobilized mixed culture of Bacillus cereus and Brevumdimonas naejangsanensis, Renewable Energy 105 (2017) 458-464.

[18] J. Lu, P.H. Toy, Organic Polymer Supports for Synthesis and for Reagent and Catalyst Immobilization, Chemical Reviews 109 (2009) 815-838.

[19] H. Golmohammadi, E. Morales-Narváez, T. Naghdi, A. Merkoçi, Nanocellulose in Sensing and Biosensing, Chemistry of Materials 29 (2017) 5426-5446.

[20] N. Cheeveewattanagul, E. Morales-Narváez, A.-R.H.A. Hassan, J.F. Bergua, W. Surareungchai, M. Somasundrum, A. Merkoçi, Straightforward Immunosensing Platform Based on Graphene Oxide-Decorated Nanopaper: A Highly Sensitive and Fast Biosensing Approach, Advanced Functional Materials 27 (2017) 1702741-n/a.

[21] J. Liu, E. Morales-Narváez, J. Orozco, T. Vicent, G. Zhong, A. Merkoçi, Bioluminescent nanopaper for rapid screening of toxic substances, Nano Research 11 (2018) 114-125.

[22] S. Giacomazzi, N. Cochet, Environmental impact of diuron transformation: a review, Chemosphere 56 (2004) 1021-1032.

[23] M. Köck-Schulmeyer, M. Villagrasa, M. López de Alda, R. Céspedes-Sánchez, F. Ventura, D. Barceló, Occurrence and behavior of pesticides in wastewater treatment plants and their environmental impact, Science of The Total Environment 458-460 (2013) 466-476. 
[24] M.A. Rippy, A. Deletic, J. Black, R. Aryal, J.-L. Lampard, J.Y.-M. Tang, D. McCarthy, P. Kolotelo, J. Sidhu, W. Gernjak, Pesticide occurrence and spatio-temporal variability in urban run-off across Australia, Water Research 115 (2017) 245-255.

[25] R. Rondon, F. Akcha, P. Alonso, D. Menard, J. Rouxel, C. Montagnani, G. Mitta, C. Cosseau, C. Grunau, Transcriptional changes in Crassostrea gigas oyster spat following a parental exposure to the herbicide diuron, Aquatic Toxicology 175 (2016) 47-55.

[26] J.S. Freitas, A. Kupsco, G. Diamante, A.A. Felicio, E.A. Almeida, D. Schlenk, Influence of Temperature on the Thyroidogenic Effects of Diuron and Its Metabolite 3,4-DCA in Tadpoles of the American Bullfrog (Lithobates catesbeianus), Environmental Science \& Technology 50 (2016) 13095-13104.

[27] G. Turnbull, J. Cullington, A. Walker, J. Morgan, Identification and characterisation of a diuron-degrading bacterium, Biology and Fertility of Soils 33 (2001) 472-476.

[28] E. Morales-Narváez, H. Golmohammadi, T. Naghdi, H. Yousefi, U. Kostiv, D. Horák, N. Pourreza, A. Merkoçi, Nanopaper as an Optical Sensing Platform, ACS Nano 9 (2015) 72967305.

[29] S. Salvestrini, P. Di Cerbo, S. Capasso, Kinetics of the chemical degradation of diuron, Chemosphere 48 (2002) 69-73.

[30] P. Wang, M. Rashid, J. Liu, M. Hu, G. Zhong, Identification of multi-insecticide residues using GC-NPD and the degradation kinetics of chlorpyrifos in sweet corn and soils, Food Chemistry 212 (2016) 420-426.

[31] A. de la Escosura-Muñiz, W. Chunglok, W. Surareungchai, A. Merkoçi, Nanochannels for diagnostic of thrombin-related diseases in human blood, Biosensors and Bioelectronics 40 (2013) 24-31.

[32] J. Liu, E. Morales-Narváez, J. Orozco, T. Vicent, G. Zhong, A. Merkoçi, Bioluminescent nanopaper for rapid screening of toxic substances, Nano Research (2017).

[33] O. Golge, B. Kabak, Evaluation of QuEChERS sample preparation and liquid chromatography-triple-quadrupole mass spectrometry method for the determination of 109 pesticide residues in tomatoes, Food Chemistry 176 (2015) 319-332.

[34] A. Masiá, J. Campo, C. Blasco, Y. Picó, Ultra-high performance liquid chromatographyquadrupole time-of-flight mass spectrometry to identify contaminants in water: An insight on environmental forensics, Journal of Chromatography A 1345 (2014) 86-97.

[35] M. Cycoń, A. Mrozik, Z. Piotrowska-Seget, Bioaugmentation as a strategy for the remediation of pesticide-polluted soil: A review, Chemosphere 172 (2017) 52-71.

[36] S. Bazot, P. Bois, C. Joyeux, T. Lebeau, Mineralization of diuron [3-(3,4-dichlorophenyl)-1, 1-dimethylurea] by co-immobilized Arthrobacter sp. and Delftia acidovorans, Biotechnology Letters 29 (2007) 749-754.

[37] S. Hokkanen, A. Bhatnagar, M. Sillanpää, A review on modification methods to cellulosebased adsorbents to improve adsorption capacity, Water Research 91 (2016) 156-173. 
[38] N. Mohammed, N. Grishkewich, R.M. Berry, K.C. Tam, Cellulose nanocrystal-alginate hydrogel beads as novel adsorbents for organic dyes in aqueous solutions, Cellulose 22 (2015) 3725-3738.

[39] N. Zhang, G.-L. Zang, C. Shi, H.-Q. Yu, G.-P. Sheng, A novel adsorbent TEMPO-mediated oxidized cellulose nanofibrils modified with PEI: Preparation, characterization, and application for $\mathrm{Cu}(\mathrm{II})$ removal, Journal of Hazardous Materials 316 (2016) 11-18.

[40] C. Zhou, Q. Wu, T. Lei, I.I. Negulescu, Adsorption kinetic and equilibrium studies for methylene blue dye by partially hydrolyzed polyacrylamide/cellulose nanocrystal nanocomposite hydrogels, Chemical Engineering Journal 251 (2014) 17-24.

[41] M.S. Da Rocha, L.L. Arnold, P.R. Dodmane, K.L. Pennington, F. Qiu, J.L.V. De Camargo, S.M. Cohen, Diuron metabolites and urothelial cytotoxicity: In vivo, in vitro and molecular approaches, Toxicology 314 (2013) 238-246.

[42] J. Fenoll, P. Sabater, G. Navarro, G. Pérez-Lucas, S. Navarro, Photocatalytic transformation of sixteen substituted phenylurea herbicides in aqueous semiconductor suspensions: Intermediates and degradation pathways, Journal of Hazardous Materials 244-245 (2013) 370379.

[43] M. Yuan, B. Liu, E. Liu, W. Sheng, Y. Zhang, A. Crossan, I. Kennedy, S. Wang, Immunoassay for Phenylurea Herbicides: Application of Molecular Modeling and Quantitative Structure-Activity Relationship Analysis on an Antigen-Antibody Interaction Study, Analytical Chemistry 83 (2011) 4767-4774. 